\title{
Author Correction: Natural and synthetic carbohydrate-based vaccine adjuvants and their mechanisms of action
}

Carlo Pifferi(i), Roberto Fuentes (10) and Alberto Fernández-Tejada (i)

Correction to: Nature Reviews Chemistry https://doi.org/10. 1038/s41570-020-00244-3 published online 25 January 2021.

In the version originally published, the stereochemistry of the fucose residue in the structure of PS B (Fig. 4a) was drawn incorrectly. This error has been corrected in the HTML and PDF versions of the article.

https://doi.org/10.1038/s41570-021-00273-6 I Published online 26 March 2021

(c) Springer Nature Limited 2021 